\title{
Network Indicators for Monitoring Intraday Liquidity in BOK-Wire+
}

\author{
Seungjin Baek* \\ Kimmo Soramäki** \\ Jaeho Yoon***
}

The views expressed herein are those of the authors and do not necessarily reflect the official views of the Bank of Korea. When reporting or citing this paper, the authors' names should always be explicitly stated.

* Payment System Stability Team, Payment \& Settlement Systems Department, the Bank of Korea, 39, Namdaemunno 3-Ga, Jung-Gu, Seoul, 100-794, Republic of Korea, E-mail: seungjin.baek@bok.or.kr

** Financial Network Analytics Ltd, Calle Bailen 33, 2-1, 08010, Barcelona, Spain, E-mail: kimmo@fna.fi *** Payment System Stability Team, Payment \& Settlement Systems Department, the Bank of Korea, 39, Namdaemunno 3-Ga, Jung-Gu, Seoul, 100-794, Republic of Korea, E-mail: jaeho.yoon@bok.or.kr

The authors are grateful to Samantha Cook (FNA) for her valuable comments and expertise in statistical methods. We also thank Joongshik Lee, Sangchul Ryoo, Beopyong Jeon, Daejung Yang, Sungguan Yun and Daeyup Lee for their comments and insights. 


\section{Contents}

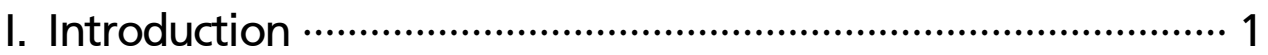

II. BOK-Wire+ and Its Network Structure …........................... 2

III. Estimating Intraday Liquidity Risks of Systemically Important Financial Institutions ………….......................... 7

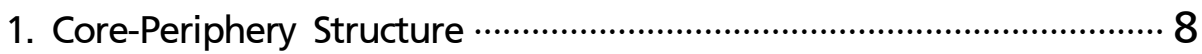

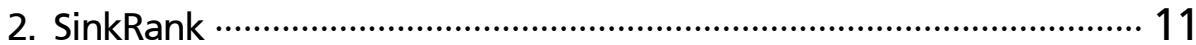

3. Intraday Liquidity Risk Monitoring Indicator

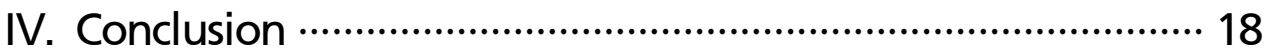

Appendix I: Calculation of SinkRank ……............................ 20

Appendix II: Regression Analysis for Expected

Debits and Credits ………................................... 21

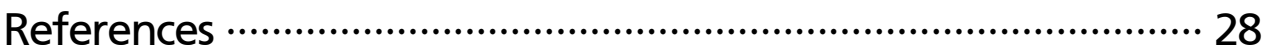




\section{Network Indicators for Monitoring Intraday Liquidity in BOK-Wire+}

In this article we describe the network properties of the Korean Interbank payment system (BOK-Wire+), apply existing methodologies for identifying systemically important banks, and develop a new intraday liquidity indicator that compares banks' expected resources for settling payments in the remainder of the day with their expected liquidity requirements. We use data only available to the Bank of Korea on banks' expected payments and build regression models for the remaining expected in- and outflows of liquidity. We find that the BOK-Wire+ system has relatively more evenly distributed payment flows than interbank payment systems in other countries. We identify ten core banks and measure their network positions (SinkRank) and intraday liquidity risks. The metrics presented in this article are especially suited for continuous oversight of intraday liquidity and systemic risks in payment systems.

Keywords: Network indicator, Intraday liquidity, Payment system, Monitoring

JEL Classification: C23, E42, G28 


\section{Introduction}

Interbank payment systems provide the backbone for all financial transactions. Virtually all economic activity is facilitated by transfers of claims by financial institutions. In turn, these claim transfers generate payments between banks whenever they are not settled across the books of a single bank. These payments are settled through interbank payment systems.

In Korea the system for settling large value payments is the Bank of Korea Financial Wire Network System (BOK-Wire+). Due to the amount of the transfers settled through it by financial institutions, and its pivotal role in the functioning of the financial markets and the implementation of monetary and credit policies, its safe and efficient functioning is central for the Korean economy.

The environment related to Large Value Payment Systems (LVPS) has changed rapidly in recent years, and the interdependency among financial institutions has increased because of the diversification of types of transactions and the expansion of securities settlement. It is thus becoming even more important for central banks to analyze the network relationships among LVPS participants.

In addition, during the global financial crisis, financial institutions' intraday liquidity situation worsened and the authorities came to recognize that intraday liquidity management is crucial for financial stability. In this context the Basel Committee for Banking Supervision (BCBS) has published "Monitoring Tools for Intraday Liquidity Management", and the Bank of Korea (BOK) is seeking to establish a robust framework for the monitoring of financial institutions' intraday liquidity management in consideration of the network relationships of the LVPS.

The object of this article is to provide a description of BOK-Wire+ with a focus on its network structure and banks' liquidity, to identify systemically important banks, and to develop a set of indicators that would allow the BOK to assess the intraday liquidity and systemic risks in BOK-Wire+. 


\section{BOK-Wire+ and Its Network Structure}

BOK-Wire+ is the real-time interbank gross payment and settlement system owned and operated by the BOK. The main feature of this system is its use not only of the RTGS mode of settlement but of a hybrid settlement mechanism1) as well. BOK-Wire+ is used for the settlement of all short-term financial transactions (general funds transfers, interbank short-term lending/borrowing, third-party funds transfers), the cash legs of securities transactions, the Korean Won (KRW) legs of foreign exchange settlements and the settlements for retail payment systems. BOK-Wire+ is also used for the implementation of BOK monetary policy operations, and for the issuance and redemption of government and other public bonds.

The daily average volume and value of funds transfers through BOK-Wire+ amounted to 13,265 transactions and 226.1 trillion KRW in 2012.2) Looking at the daily average value of funds transfers made through BOK-Wire+ by time of day, in Figure 1 (left), more than half of all settlements are concentrated between 4:00 p.m. and closing time (5:30 p.m.). ${ }^{3)}$ Settlement concentration near the closing time is a potential risk factor in the operation of BOK-Wire+. If settlement transactions are heavily concentrated during the last hour of operation, settlement gridlock is highly likely. This could cause a failure to complete daily settlement because of a lack of time to resolve the situation, which might in turn result in systemic risk.

The maximum intraday liquidity usage ratio (MLU4)) of all banks (from January 2, 2007 to September 28, 2012), which indicates banks' intraday liquidity usage relative to their intraday liquidity sources, was high during the global financial crisis, but returned to stable levels after the cuts of the Base Rate between October 2008 and February 2009. This means that banks managed their intraday liquidity more tightly in a stressed market situation.

1) A hybrid settlement system combines the characteristics of an RTGS system and a netting system by adding bilateral and multilateral offsetting features to the RTGS system.

2) The daily average volume and value are calculated with all transactions settled through BOK-Wire+. In contrast, transactions between the accounts of an individual institution are excluded when computing the network indicators in Table 1.

3) See "Payment and Settlement Systems Report 2012" (BOK) for more details.

4) $\mathrm{MLU}_{\mathrm{t}}=\frac{\sum_{i}^{n} \text { value of maximum intraday liquidity usage of bank_i at day } t}{\sum_{i}^{n}(\text { starting balance }+ \text { credit limit }) \text { of bank_i at day } t}$ 
Figure 1: Proportions of settlement through BOK-Wire+, by time of day (left), and maximum intraday liquidity usage ratio of all banks (right)
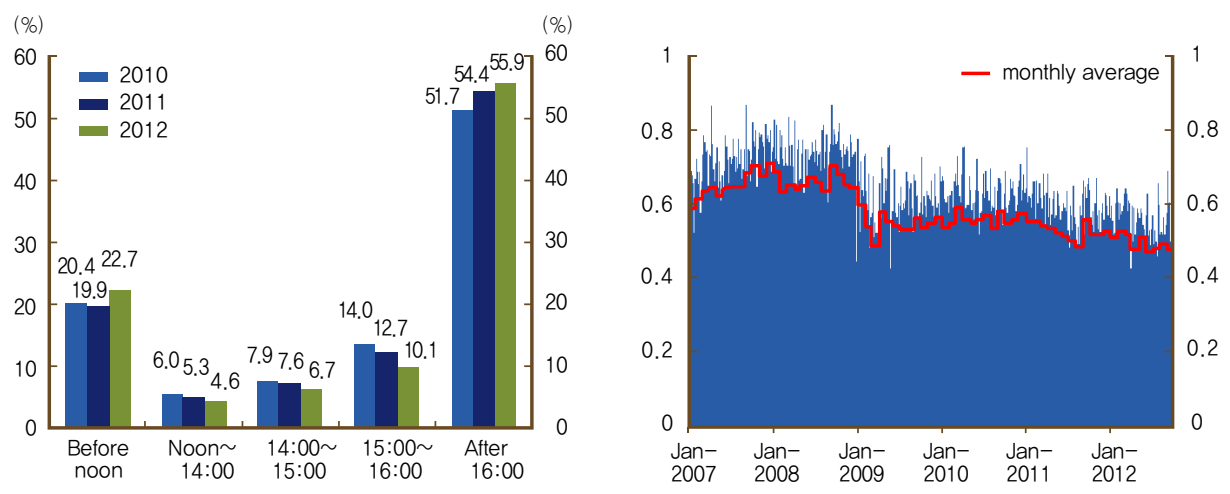

Note: The proportions of the daily average values of fund transfers through BOK-Wire+ for 2010, 2011 and 2012 are drawn with blue, dark blue and green bars by time of day in the lefthand figure. In the righthand figure, the blue bars show the MLUs of each day and the red line represents the average monthly MLUs.

Recently regulators and researchers have begun to understand and analyze payment systems through the lens of network theory. The general concept of a network is highly intuitive: a network describes a collection of nodes (e.g. financial institutions) and the directed links among them. The links can denote different relationships between the nodes, depending upon the domain of analysis. In our context of a payment system, a link describes the value of payments sent by one institution to another on a given day.

The main premise of network analysis is that the structure of the links between the nodes matters for the systemic importances and liquidity risks posed by participants in the network. Earlier analyses applying network concepts to interbank payment systems include e.g. Soramäki et al. (2007) for payment flows in the US Fedwire system, and Becher et al (2008) for the UK, Pröpper et al. (2009) for the Dutch, Boss et al. (2009) for the Austrian, and Embree and Roberts (2009) for the Canadian interbank payment system.

Table 1 shows a comparison of network metrics across selected interbank payment systems.5) The BOK-Wire+ system has 125 participants, i.e. in the same range as the Dutch TOP system. Around 18\% of the possible links are used on a

5) All metrics were calculated and the modeling was carried out with FNA software (www.fna.fi). 
daily basis, a relatively large share compared to that of the TOP - probably a result of the less concentrated banking market in Korea. The Canadian LVTS is tiered, with 14 large banks acting as correspondents to a number of smaller banks which may be interacting either with the LVTS members or other smaller banks using the LVTS members to settle large-value payments. The network therefore has very high connectivity; it is almost a complete network, where all possible links are present. The connectivity in Fedwire is much lower, at $0.3 \%$, due to the large number of possible links ${ }^{6)}$ in a network of 5,086 banks on average, and to the high concentration of payment activity among the most connected banks.

On average, participants in BOK-Wire+ transfer payments with 23 other participants, as the most connected participants receive payments from 84 counterparts and send payments to 86 . Reciprocity, i.e. the share of reciprocal links, is very high. At $58 \%$ it is over three times what would be expected in an Erdős-Rényi (ER)7) network with the same connectivity (the expected reciprocity in such a network is its connectivity, i.e. in the case of BOK-Wire+ 18.1\%). The high share of reciprocal links may be caused for example by preferential business relationships or similar business activities (Soramäki et al 2007), or by the co-ordination of payments and liquidity (Embree and Roberts 2009). Like most payment networks, the BOK-Wire+ network is very dense. The average path length from one node to another is only 1.85 and even the most remote participants in the network are only a few steps from each other - resulting in an average diameter of 3.8 in the network.

The clustering coefficient in BOK-Wire+ is high at 59.9\%. The clustering coefficient measures the likelihood that two connections of a participant are connected as well - forming a triangle. $\left.{ }^{8}\right)$ This concept originates from social network analysis, showing that the friends of any one person are often more likely to be friends as well.

6) The number of possible links in a network is $n^{*}(n-1)$. In the case of Fedwire this is 25.9 million. Considering that the volume of transactions is 345,000 it is clear that connectivity must be low even without any concentration of payments (which is also high in Fedwire as can be seen in Figure 3).

7) In an Erdős-Rényi (ER) model a network is constructed by connecting nodes randomly so that each node has an equal probability of being the source and target of a link. This model is often used as a benchmark to identify non-random network structures.

8) Following Soramäki et al (2007) we calculate the clustering coefficient for each node as $C_{i}=\frac{m_{n n, i}}{k_{i}\left(k_{i}-1\right)}$ where $m_{n n, i}$ is the number of links between neighbors of node $\mathrm{i}$ and $k_{i}$ is the number of neighbors of node i (i.e., its degree). 
Extended to banking systems, we see in BOK-Wire+ and the compared systems that this type of clustering is also very common here. This could be due to the fact that most banks connect to a small set of core banks which are connected to each other - forming triangles in which two of the banks concerned are in the core and one in the periphery. ${ }^{9)}$ The expected clustering co-efficient in a random ER network is its connectivity, i.e., less than one-third of what we find for BOK-Wire+.

The BOK-Wire+ network is characterized every day by a single strongly connected component allowing liquidity to flow freely in the network. This contrasts with many other economic networks (see e.g. Vitali et al 2011) that have bow-tie structures, where some of the nodes are in components where liquidity flows out to the strongly connected components, and certain of the participants are in components that receive liquidity from the strongly connected components. Such a structure was also found for the Fedwire system, where $21 \%$ of the participants did not belong to the strongly connected component (Soramäki et al 2007).

Table 1: Comparison of network properties of selected interbank payment systems (daily averages and standard deviations)

\begin{tabular}{c|c|c|c|c} 
System & BOK-Wire+ (Korea) & LVTS (Canada) & TOP (Netherlands) & Fedwire (US) \\
\hline Time Period & August 2013 & 4/2004-12/2008 & $6 / 2005-5 / 2006$ & 2005 \\
\hline Value & 190 trillion KRW & 25.4 trillion CAD (year) & 584 million EUR & 1.3 trillion USD \\
\hline Volume & 11,672 & $4.4 \mathrm{M}$ (year) & 21,400 & 345,000 \\
\hline Number of nodes & $122 \pm 5.9$ & 14 & 155 & $5086 \pm 123$ \\
\hline Number of links & $2,871 \pm 471$ & $\mathrm{n} / \mathrm{a}$ & 1,182 & $76,614 \pm 6151$ \\
\hline Connectivity (\%) & $18.1 \pm 2.5$ & $69.2 \pm 3.3$ & 7.0 & $0.3 \pm 0.01$ \\
\hline Degree (average) & $45.4 \pm 6.9$ & $\mathrm{n} / \mathrm{a}$ & 9.2 & $15.2 \pm 0.8$ \\
\hline Degree (maximum in) & $84 \pm 8$ & $\mathrm{n} / \mathrm{a}$ & $\mathrm{n} / \mathrm{a}$ & $2,097 \pm 115$ \\
\hline Degree (maximum out) & $86 \pm 10$ & $\mathrm{n} / \mathrm{a}$ & $\mathrm{n} / \mathrm{a}$ & $1,922 \pm 121$ \\
\hline Reciprocity (\%) & $58 \pm 6.0$ & $89.3 \pm 2.5$ & 63 & $21.5 \pm 0.03$ \\
\hline Average path length & $1.85 \pm 0.05$ & $1.31 \pm 0.03$ & $\sim 2.3$ & $2.62 \pm 0.02$ \\
\hline Average eccentricity & $2.9 \pm 0.1$ & $1.84 \pm 0.07$ & $\sim 3.3$ & $4.67 \pm 0.33$ \\
\hline Average diameter & $3.8 \pm 0.4$ & $2.01 \pm 0.07$ & $\mathrm{n} / \mathrm{a}$ & $6.6 \pm 0.5$ \\
\hline Clustering coefficient (\%) & $51.3 \pm 1.7$ & $84.3 \pm 1.5$ & 38.0 & $53.0 \pm 1$ \\
\hline
\end{tabular}

Sources: LVTS (Embree and Roberts, 2009), TOP (Pröpper et al., 2009), Fedwire (Soramäki et al., 2007). Not all papers report all metrics. Unavailable metrics are marked as $n / a$ in the table. For TOP, the standard deviations of the metrics are not available.

9) We discuss the core-periphery structure of the network in the next section. 
Visualizing dense networks is difficult. One approach is to remove the insignificant links. Figure 2 shows the effects of this approach for a typical day (20 August 2013) in BOK-Wire+. We start the series with the full network, and in subsequent frames keep only the largest links covering 99\%, 95\%, 90\%, 75\% and $50 \%$ of the total payment value. The full network contains many very small links that are not likely to be important for risks and liquidity flows. The smallest links, which together account for $1 \%$ of in total payment value, make up over a third of all links. The effect gets smaller as more of the small links are stripped out and the 'core' of the network is 'peeled out'.

Figure 2: Effects on network structure of removing small value links

All Links

126 participants, 2,973 links

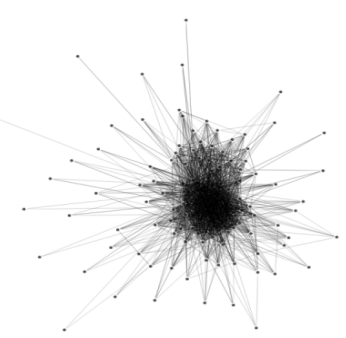

Top $90 \%$ of links

89 participants, 934 links

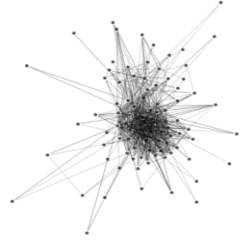

Top $99 \%$ of links

111 participants, 1,820 links

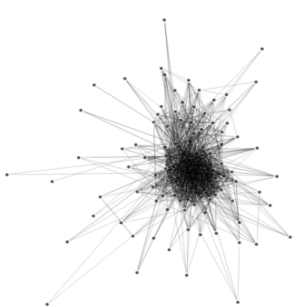

Top $75 \%$ of links

70 banks, 498 links
Top $95 \%$ of links

104 participants, 1,247 links

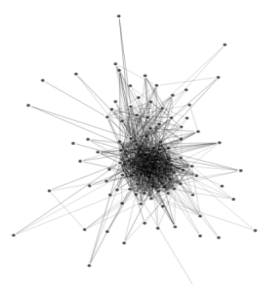

Top $50 \%$ of links

33 participants, 189 links

Note: Each figure shows the network structure containing the largest links, covering 99\%, 95\%, $90 \%, 75 \%$ and $50 \%$ respectively of the total payment value.

Figure 3 below displays the largest links accounting for $75 \%$ of the payments of BOK-Wire+ (left) and in Fedwire in 2004 (right). In BOK-Wire+ 70 participants and 
286 undirected links, ${ }^{10)}$ and in Fedwire 68 participants and 181 links form these sub-networks. While the sub-networks are similarly sized in terms of their numbers of nodes, it is clearly seen that there are more links and that the link values (links with higher values are shown as thicker widths of links) are more evenly distributed in BOK-Wire+ than they were in Fedwire.

Figure 3: Comparison of undirected links accounting for $75 \%$ of value
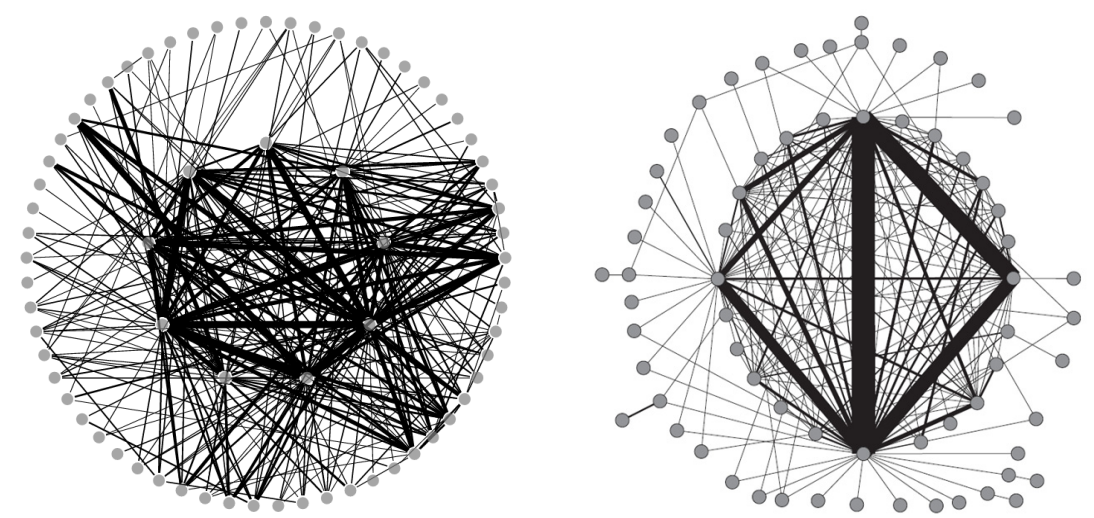

Note: The sub-networks of BOK-Wire+ and Fedwire (Soramäki, et al 2007), made up of the largest undirected links covering $75 \%$ of their total payment values, are shown on the left and the right respectively.

\section{Estimating Intraday Liquidity Risks of Systemically Important Financial Institutions}

As may be seen from Figure 3, which shows the BOK-Wire+ network structure, the core of the network is composed of only a limited number of participants and they are tightly connected with each other. It is important for central banks to recognize which of the participants are systemically important, and to monitor their intraday liquidity situations properly to ensure the smooth functioning of the LVPS. In this context, we identify systemically important participants in BOK-Wire+ through

10) For a better comparison with the Fedwire-network, the Bank of Korea is excluded in this diagram and the 498 directed links are summed into 286 undirected links. 
Core-Periphery analysis (Craig and von Peter, 2010) and SinkRank (Soramäki and Cook, 2013), and analyze their intraday liquidity risks using a new indicator developed in this paper - the Payment System Liquidity Indicator (PS-LI). ${ }^{11}$ )

\section{Core-Periphery Structure}

Craig and von Peter (2010) introduced the concept of core-periphery, or tiered, structures for banking systems. The concept entails a small group of highly-connected core participants and a larger group of less-connected periphery participants. Many central banks and researchers have since applied this methodology, for example in pursuit of identifying a set of systemically important banks. A perfect core-periphery system has the following properties:

- The core banks are connected to each other.

- The periphery banks are not connected to other periphery banks.

- The core banks are connected to (some) periphery banks.

Craig and von Peter (2010) present an algorithm for approximating the coreperiphery structure. The algorithm finds the classification of banks into a 'core' and a 'periphery' that minimizes the error score, for nodes classified as periphery the error is equal to the numbers of links that they have to other nodes classified as periphery, and for nodes classified as core the error is equal to the numbers of missing links to other nodes classified as core. The classification error is the sum of the nodes' errors.

Real banking systems deviate from perfect core-periphery structures, with some core banks not linked to all other core banks or some links present between periphery banks. Nevertheless, the core-periphery concept has proved useful for understanding markets and banking systems and for identifying important banks. For example, Craig and von Peter (2010) found a core-periphery structure in the German

11) We used settlement data of BOK-Wire+ from August 1, 2013 to August 30, 2013 for calculating the Core-Periphery structure and SinkRank, and from July 1, 2013 to September 30, 2013 for PS-LI. 
banking system, while also finding that bank-level features such as connectedness and balance sheet size were helpful for predicting a bank's classification as core or periphery. The finding that large, well-connected banks are more likely to be in the core lends support to the core-periphery structure as a realistic model for banking systems. Craig and von Peter also found that the core-periphery classification of banks in the Germany system is stable over time. Fricke and Lux (2012) meanwhile reported similar findings for the e-MID trading platform, and Langfield et al. (2013) reported a core-periphery structure in the UK interbank system.

We calculate the core-periphery structure for BOK-Wire+ and find that the model fits the data relatively well. The error rate (number of errors divided by number of links on a given day) is on average $17.1 \%$, with a relatively small standard deviation of $1 \%$. In comparison, the average error rate in a random ER network with the same number of nodes and links is much higher at $73 \%$. The error rate reported by Craig and von Peter (2010) for the German banking network is in the same range, although slightly smaller at $12.2 \%$. We can also compare the error with the network built with a Barabasi-Albert model of growth and preferential attachment adapted for payment systems by Soramäki and Cook (2013). Such a scale-free network exhibits a small number of highly connected nodes that form the core, and a large number of nodes that connect to these. In a network built with this algorithm, and having roughly the same number of links, the error is smaller at $6.2 \%$. The Korean interbank network can be said to be close to a core-periphery structure, but not as close as a scale-free network would be. 
Figure 4: Core-periphery structure of complete BoK-Wire+ network

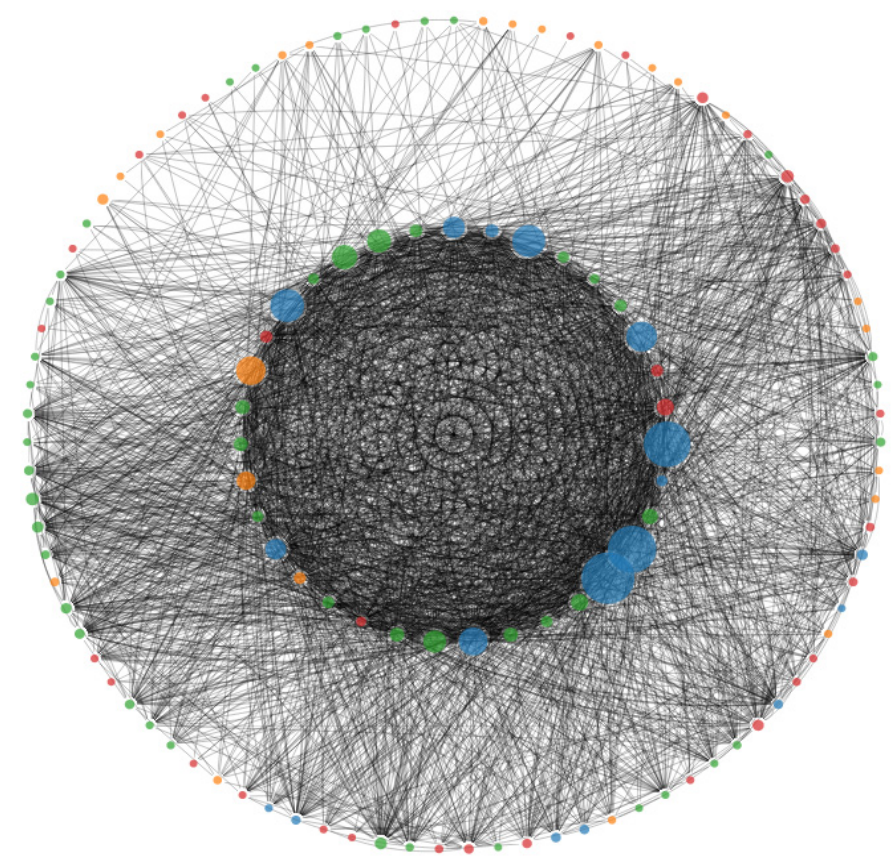

Note: Nodes denote participants, and links net payment flows between participants. The sizes of the nodes are commensurate with the values of payments sent and received by the participants concerned. The nodes are colored in accordance with the groups ${ }^{12}$ ) that the participants belong to: Blue $=$ Domestic banks, Red = Foreign Bank Branches, Green = Financial Investment Companies, Orange $=$ Other.

The figure above shows the core-periphery structure of BOK-Wire+ on a representative day (20th August 2013). Depending upon the day, we find between 20 and 37 core banks and between 85 and 96 periphery banks. ${ }^{13)}$ The core banks

12) Financial institutions in Korea are commonly divided into six categories: banks, non-bank depository institutions, financial investment companies, insurance companies, other financial institutions, and financial auxiliary institutions. Based upon the Acts applicable to them, financial institutions providing similar services are grouped together. However, banks and financial investment companies perform key roles in the payment and settlement services, and there are unique differences between domestic banks and foreign bank branches regarding these services. We thus classify the participants of BOK-Wire+ into four groups in this paper: domestic banks, foreign bank branches, financial investment companies, and others.

13) Without taking into account Wednesday 7 August the structure is even more stable with between 33 and 37 core banks each day. The Wednesday of the second week of every month is the last day of the reserve maintenance period. Banks are often reluctant to settle transactions so as not to change their current 
are mostly domestic banks and financial investment companies. In relative terms, $59 \%$ of domestic banks are in the core. From financial investment companies 19\% are in the core, from Others $13 \%$ and from Foreign bank branches only $6 \%$ (across the whole time period).

The structure is also found to be very stable across days, as the standard deviation of the error rate is very low. We find a total of 49 banks in the core on at least one day. Half of these are in the core on either all days or all but one. We find ten banks that are in the core on all of the 21 business days of August.

\section{SinkRank}

The metrics most often used for measuring the systemic importances of banks in a payment system tend to focus on local measures, such as the numbers or values of payments made or received, and ignore the system's network structure. Networkbased centrality measures can give a more complete description of the importances of banks in the network. However the existing network-based metrics have been developed with other applications in mind, and do not capture the salient features of payment systems, such as their dependence on smooth flows of liquidity reused by banks several times over the course of the settlement day to settle payments. Soramäki and Cook (2013) aim to improve this by presenting a new algorithm, SinkRank, for identifying the central nodes in payment systems.

SinkRank models the liquidity flows in the system using absorbing Markov Chains in a directed and weighted network. The transition matrix for the Markov Chain-model is estimated on the basis of historical payment patterns. Each payment moves liquidity in the network, and the measure of interest in SinkRank is the number of random payments (along the links in accordance with their historical frequencies) that are needed to transfer a unit of liquidity anywhere in the network to the given 'Sink' node. The faster liquidity moves to the sink node, the more important it is and the higher its SinkRank. The matrix algebra for calculating

account balances at the BOK on these days, and so the volumes and values of funds transfers through BOK-Wire+ are much smaller then than on other days. 
SinkRank is described in detail in Appendix I.

Comparing core banks and banks with the highest SinkRanks, we first see that the five banks with the highest average SinkRanks are also core banks. The 19 banks with the highest average SinkRanks are core banks on either all days or all but one day. The two measures thus point to the same conclusion.

Figure 5: SinkRanks and frequency of system participants present in the Core

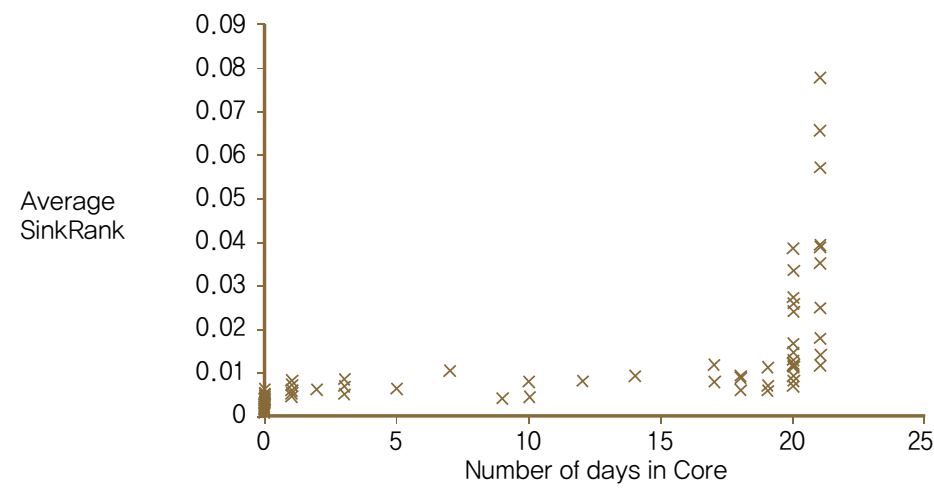

Note: This graph shows the relationships between the daily average SinkRanks of the BOK-Wire+ participants and the numbers of days on which they are classified as core banks under the core-periphery structure.

The added benefit of SinkRank is, however, that it is on an interval scale and so can be used to identify outliers. A few banks have relatively high SinkRank scores even where they are only identified in the core on small numbers of days, and some banks that are frequently in the core have relatively low SinkRank scores. As can be seen in Figure 6, SinkRank is positively correlated with the value of payments sent and received by a bank. We see one trajectory of SinkRank values (in red) that is different from the others. In these observations, participants with relatively low payment values have high SinkRank values. These are values for a number of participants on the last day of the reserve maintenance period (7 August), and in fact the highest SinkRank for the whole period is observed on this date. 

Figure 6: SinkRanks and values of payments sent and
received by system participants

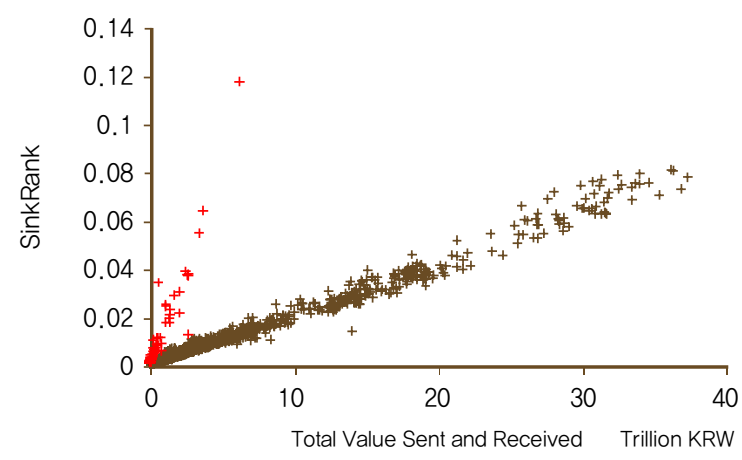

Note: This graph shows the daily relationships between the SinkRanks of the BOK-Wire+ participants and the total values sent and received by them.

The SinkRank values of participants are highly skewed. Some $62 \%$ of participants have SinkRanks of less than 0.01 , meaning that it takes on average 100 payments to move liquidity to the participant from a random other participant in the network. For $95 \%$ of banks their SinkRanks are below 0.04, meaning 25 payments on average to move liquidity to the sink from a random starting point in the network. The highest SinkRank of a participant during the month was 0.12. On this day only eight payments on average were needed to move liquidity to that participant from any other participant.

As already mentioned, the Core-Periphery structure and SinkRank yield the almost same conclusions on systemically important participants in BOK-Wire+. We focus our further analysis now on ten banks that were in the core on all business days of August.

\section{Intraday Liquidity Risk Monitoring Indicator}

SinkRank measures the importances of banks' network positions. It does not evaluate whether a bank has the capacity to process payments or to withstand intraday liquidity shocks without propagating them further. To evaluate the bank's 
payment capacity we utilize a unique dataset on trading data to develop a new metric called PS-LI (Payment System Liquidity Indicator), which captures both a bank's payment needs and its capacity to carry out payments.

For banks, the intraday liquidity sources consist of their reserve balances at the central bank $\left(\right.$ Balance $\left._{i j t}\right)$, their intraday credit limits at the central bank $\left(\right.$ Limit $\left._{i j t}\right)$ at time t on day $j$ and their payments to be received from other financial institutions during the remainder of day $j$ at time $t$ (remaining credits, Rcredits $_{i j t}$ ). Their intraday demand for liquidity comes from payments to be made to other financial institutions during the remainder of day $j$ at time $t$ (remaining debits, Rdebits ${ }_{i j t}$ ). Financial institutions manage their intraday liquidity risks by maintaining the inequality:

$$
\text { Balance }_{i j t}+\text { Limit }_{i j t}+\text { Rcredits }_{i j t}>\text { Rdebits }_{i j t}
$$

i.e. a bank's intraday liquidity sources must be larger than its intraday liquidity demands. Note that a bank's balance, Balance $_{i j t}$, can be either positive or negative up to the Limit ${ }_{i j t}$ (which is denoted as a positive number here).

The BOK knows the reserve balances that banks hold at the BOK and the intraday credit limits that they have from the BOK on a real-time basis. Often banks themselves or central banks do not know the values of all payments that banks needs to make during the remainder of a day. The BOK, however, can access information on some payments related to securities settlement and foreign exchange (FX) settlement in advance, since they are reported to the BOK before the hours of operation on the settlement date by other institutions such as the Korean Central Counterparty (CCP) and the Central Securities Depository (CSD), and by the Continuous Linked Settlement system (CLS) for FX settlement. In addition, some payments remain pending before they are settled, and must be included in the liquidity demand. In light of this information, the above inequality can be revised as follows:

$$
\begin{array}{r}
\text { Balance }_{i j t}+\text { Limit }_{i j t}+\text { KRcredits }_{i j t}+\text { ERCredit }_{i j t} \\
>\text { Pending }_{i j t}+\text { KRdebits }_{i j t}+\text { ER }_{\text {debit }} s_{i j t}
\end{array}
$$


which splits the remaining credits and debits into two components, KRcredits and KEdebits that are known by the BOK in advance due to the reporting by market infrastructures, and ERcredits and ERdebits which are unknown but can be estimated on the basis of historical payment patterns. In this paper we use linear regression models as described in Appendix II to estimate these values. The models take into account day of the week effects, the value already settled on the given day, effects related to reserve maintenance and to US holidays, and the trade values of bonds and spot exchange, and provide accurate estimates for the values of expected credits and debits.

Finally, we use the above inequality for calculating the intraday Payment System Liquidity Indicator (PS-LI), as bank $i$ 's ratio of projected liquidity demand to projected liquidity supply at time t on day $j$ :

$$
P S-L I_{i j t}=\frac{\text { Pending }_{i j t}+\text { KRdebits }_{i j t}+\text { ERRebit }_{i j t}}{\text { Balance }_{i j t}+\text { Limit }_{i j t}+\text { KRcredits }_{i j t}+\text { ERcredit }_{i j t}}
$$

If the PS-LI of a given bank at a given time is greater than 1, the bank's expected liquidity needs are larger than its available resources and the bank is likely to experience high intraday liquidity pressure. If the value is less than 1, the bank's liquidity resources at the given time are sufficient to cover its expected intraday liquidity demand during the remainder of the day.

We can classify the core participants into three groups depending upon their PS-LIs: participants with PS-LIs at 9:00 a.m. of over 1, between 0.8 and 1, and below 0.8.14) Participants with high PS-LIs can be considered to have high probabilities of being subject to intraday liquidity risk and, correspondingly, those with low PS-LI have low probabilities.

14) As mentioned above, a bank with a PS-LI over 1 at a given time is not expected to have sufficient intraday liquidity sources to fulfill all of its expected payment obligations, and so such a case is somewhat extreme. In this context, we assume that if the PS-LI of a bank is greater than 0.8 the bank uses intraday liquidity sources to the full and the BOK needs to monitor this bank. We find 2,016 such cases out of 11,780 observations during the third quarter of 2013. 
Figure 7: Levels and volatilities of core banks' PS-Lls
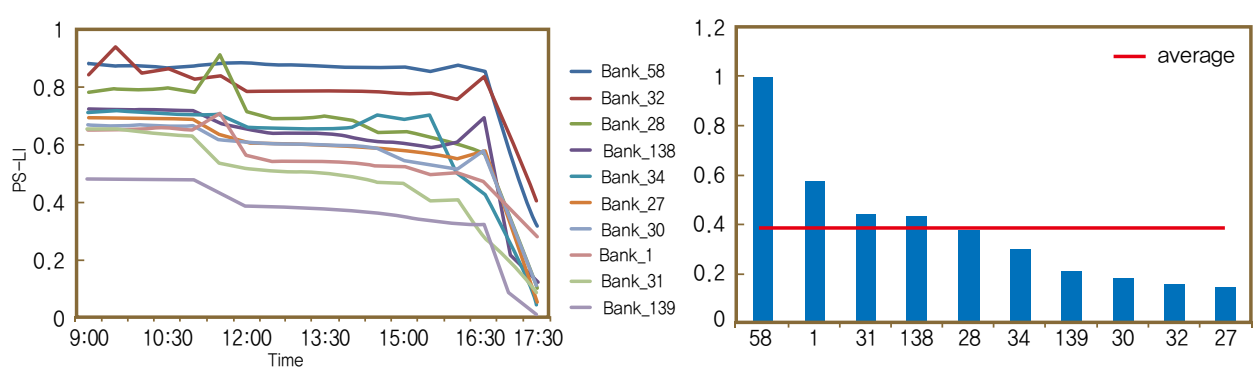

Note: The daily average levels of PS-Lls of the different banks are drawn in the lefthand figure, by time of day, and the volatilities of their PS-Lls (blue bars) and their averages (red line) in the righthand figure.

In addition to the absolute level of the PS-LI, its volatility15) is of interest and can represent a bank's character regarding intraday liquidity management, and it is likely that banks with high PS-LI variabilities may have challenges in intraday liquidity management. When looking at the payment and liquidity patterns of banks we in fact find that banks 58, 1, 28 and 31, whose volatilities in terms of PS-LI are above average, have the least amounts of intraday liquidity sources.

With these two dimensions we can classify the ten core banks into six groups. This could be interpreted as indicating that the banks in the shaded cells are likely to have relatively high intraday liquidity pressures, so that the BOK needs to monitor them more carefully:

\section{Table 2: Classification of banks by level and volatility of PS-LI}

\begin{tabular}{l|c|c|c|c}
\hline \multirow{3}{*}{ Volatility } & \multicolumn{3}{|c}{ Level } \\
\cline { 2 - 5 } & Above average & Above 1 & Between 0.8 and 1 & Below 0.8 \\
\cline { 2 - 5 } & Below average & - & 58 & $1,28,31,138$ \\
\cline { 2 - 5 } & - & 32 & $27,30,34,139$ \\
\hline
\end{tabular}

Note: This table shows the classification of banks by their daily average PS-LI levels at 9:00 a.m. and the volatilities of their PS-LIs. The BOK needs to monitor the banks in the shaded cells more carefully.

15) We calculate the PS-LI volatility of a certain bank by summating the variance of PS-LI of that bank every 30 minutes from 9:00 a.m. until 5:30 p.m. 
A further framework for understanding intraday liquidity risk and potential contagion is the quadrant presented in Figure 8. This plots SinkRank versus PS-LI (at 9:30 A.M.) and divides the plot area into four regions. In the bottom left area both the SinkRank and the PS-LI are low, indicating that these banks do not have prominent network positions as regards their capacities to disrupt the system and have sufficient resources to cover their expected intraday liquidity requirements. These banks pose the smallest risk and account for $31 \%$ of the observations. On the top left ( $20 \%$ of total observations) we have those banks with important positions in the network but sufficient resources. On the bottom right ( $30 \%$ of total observations) are banks with relatively more limited resources but not important network positions. And on the top right are the banks that are most systemically important and most constrained in their resources, which would thus pose the greatest risk to the system. About $18 \%$ of the observations are present in this quadrant. In the right panel of Figure 8 we see the average positions of individual banks in terms of their PS-LIs and SinkRanks and find that only one bank is in the most risky quadrant even though several other banks are very close to it.

Figure 8: Intraday liquidity risks (PS-LI) and Importances (SinkRank) of ten core banks on individual days (left) and on average (right) at 9:00 a.m.
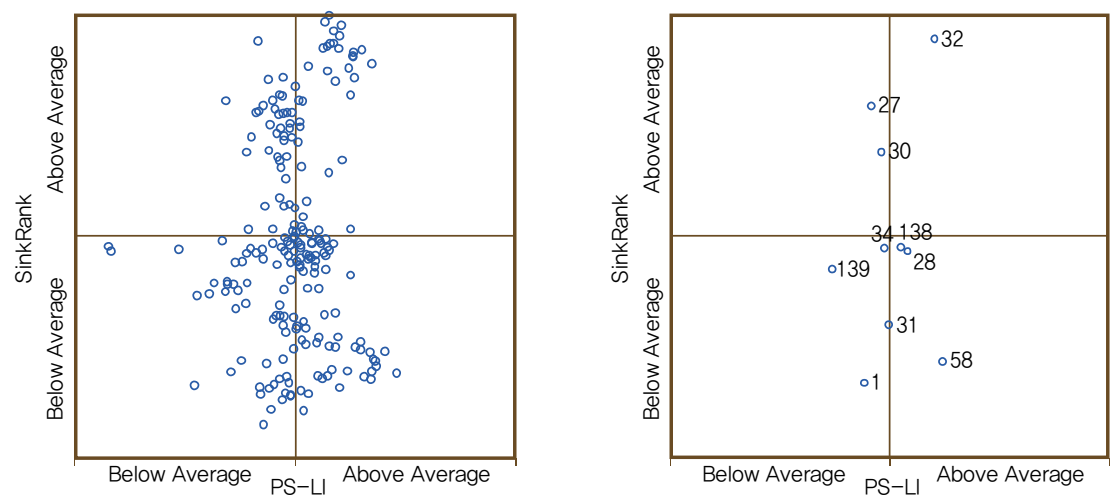

Note: Each blue dot represents a participant's PS-LI at 9:00 a.m. versus its SinkRank on a certain day in the lefthand figure, and a participant's daily average PS-LI at 9:00 a.m. versus its daily average SinkRank in the righthand figure. 


\section{Conclusion}

In this paper we described the network properties of the Korean interbank payment system, and found them to be similar to those of other interbank payment systems studied. The system has more evenly distributed flows and relatively more banks that are important from a systemic perspective. From a total of 132 central bank account holders, we identified the core and periphery of the network and found the model presented in Craig and von Peter (2010) to fit the data well. We found the core to be relatively stable over the days, and studied the ten banks that were in the core on each of the days in the month of August 2013.

In the second part of the paper, we identified the most important banks in terms of their network positions, using the SinkRank algorithm developed in Soramäki and Cook (2013). Unsurprisingly, we found that core banks have higher SinkRank scores. Because neither the Core-Periphery analysis nor the SinkRank metric evaluate whether a bank has the capacity to process payments or to withstand intraday liquidity shocks without propagating them further, we then developed a new metric named the Payment System Liquidity Indicator (PS-LI), which compares a bank's expected resources for settling payments in the remainder of the day with its expected liquidity requirements. We used data on banks' expected payments available only to the BOK and built regression models for the remaining expected in- and outflows of liquidity for each day. Using these together with SinkRank (systemic importance of the bank) and PS-LI (intraday liquidity risk), we were able to identify the banks that are most critical to the smooth functioning of the system.

Our work has made several contributions. First, we have suggested new metric appropriate for continuous oversight of intraday liquidity and systemic risks in payment systems. Most payment system monitoring indicators can only be calculated after the end of payment system operation on the settlement date, because actual settlement data is required to compute them. In contrast, our PS-LI can be calculated on a real-time basis during operating hours by using information on some payments related to securities and FX settlements which the BOK can assess in advance, and estimating the remaining credits and debits, and can thus be used for timely monitoring of the intraday liquidity risks of participants in BOK-Wire+. 
Second, we have studied the network structure of BOK-Wire+ and compared it with those of other LVPSs. The BOK-Wire+ network is characterized by a single strongly connected component allowing liquidity to flow freely in the network, similarly with other LVPSs, but it has a difference in that the link values between participants located in core are more evenly distributed than they were in Fedwire.

This research can be extended in several ways. First, the model of liquidity flows underlying the SinkRank metric could be (like the PS-LI) made time-dependent and based on regression models of expected flows in the complete system. Verification of the results is hard because actual disturbances are rare. In such cases the theoretical and statistical underpinnings have more importance. We believe that both the SinkRank and the PS-LI correctly measure the systemic importance and liquidity risk per their construction. However, it would be interesting to carry out counterfactual simulations where a number of different stress scenarios are simulated and the disruption measured and compared to the SinkRank and PS-LI values of failing banks. Second, regression analysis could be improved by enabling the estimation of parameters of the regression model to be adjusted in reflection of the stress situation. This improvement might be useful in predicting banks' intraday liquidity situations under stress, because the parameters of the regression model in this paper are estimated on the assumption of the market situation being the same as usual. 


\section{Appendix I: Calculation of SinkRank}

We can represent the network of interest as a matrix $M$, where the rows and columns correspond to the nodes which, for convenience, we'll label as $1,2, \ldots n$. The $i, j t h$ entry of the matrix corresponds to the link from node $i$ to node $j$. If there is no link from node $i$ to node $j$, that entry of the matrix is equal to 0 . Otherwise, the $i, j t h$ entry of the matrix is equal to the weight of the link from node $i$ to node $j$. We use as weight the value of payments sent by bank $i$ to bank $j$ on the day for which the measures are calculated. We then calculate the transition matrix of the system, $P$, by dividing each entry by its row sum.

To calculate the SinkRank, we number the nodes so that the absorbing node (i.e. the node for which the SinkRank is calculated) comes last in the transition matrix. The transition matrix of the absorbing system is then equal to $P^{\prime}=\left[\begin{array}{ll}S & T \\ 0 & I\end{array}\right]$ where $\mathrm{S}$ is a square $(n-1) \times(n-1)$ matrix, 0 is a row vector (length $n-1$ ) of zeros, and $T$ is a column vector of length $n-1$. We then calculate the fundamental matrix $Q=(I-S)^{-1}$. The row sums of $Q$ correspond to the expected number of steps before absorption for each possible starting value. We calculate the SinkRank of the absorbing node as the inverse of the simple average of $Q$ 's row sums, i.e. $\frac{n-1}{\sum_{i} \sum_{j} q_{i j}}$. To calculate the SinkRanks for all nodes, we repeat the above process, setting each node in turn as the absorbing node. 


\section{Appendix II: Regression Analysis for Expected Debits and Credits}

This Appendix details the linear regression procedure used to calculate the expected remaining credit and debit values used in the PS-LI indicator. We first computed the expected total credit (and debit) values by using regression results, and then obtained the expected remaining credit (and debit) values by using the expected total credit (and debit) values and the cumulative credit (and debit) values. These expected values were calculated at half-hour intervals for all business days in the third quarter of 2013.

\section{Expected Remaining Credits}

\section{Step 1. Calculating Expected Total Credits Using Regression Model}

To calculate the expected total credits to a bank, we fit a linear regression model (Model 1) with the total credit as the response variable, and the bank, the day of the week and indicators for reserve maintenance days and US holidays, and the trade values of bonds and spot exchange as predictors. More specifically, we fit the model below:

$$
\text { Tcredit }_{i j}=\beta_{i}^{\text {credit }}+\gamma^{\text {credit }} D_{j}+\delta^{\text {credit }} R_{j}+\zeta^{\text {credit }} U_{j}+\eta^{\text {credit }} \text { Bond }_{j}+\theta^{\text {credit }} F X_{j}+\epsilon_{i j}
$$

where Tcredit $_{i j}$ represents the total credits to bank $i$ 's settlement account on day $j ; \beta_{i}^{\text {credit }}$ is a constant effect for bank $i ; \gamma^{\text {credit }}$ is a vector of day of the week effects and $D_{j}$ a vector of day of the week indicators for day $j ; R_{j}$ is an indicator of whether day $j$ was the last day of the reserve maintenance period; $D_{j}$ is an indicator of whether day $j$ was a US holiday; $B o n d_{j}$ is the trade value of bonds on day $j-1{ }^{16)} ; F X_{j}$ is the trade value of spot exchange on day $j-2^{17)}$; and $\epsilon_{i j}$ is an

16) The settlement date for bonds is commonly one business day after the transaction date.

17) The settlement date for FX (US dollar) is commonly two business day after the transaction date. 
error term, assumed to be normally distributed with different variance for each bank (heteroscedasticity).

We estimated the parameters of the above model by using fixed effect panel regression under heteroscedasticity with the data from ten banks (ids 1, 27, 28, 30, 31, 32, 34, 58, 138 and 139) from 1 July 2012 to 30 June 2013. All coefficients of Model 1 except for the trade values of bonds and spot exchange were statistically significant at significance levels of $5 \%$, and the model's adjusted R-squared was equal to 0.9668 . We re-estimated the revised model (Model 2) excluding the trade values of bonds and spot exchange, and found that all regression coefficients were statistically significant with p-values less than 0.039 , and that the model's adjusted R-squared was equal to 0.9669 .

Using the estimated parameters and information on the independent variables of the two models - the day of the week, the last day of the reserve maintenance period and US holidays, the trade value of bonds and the trade values of spot exchange for Model 1, and the day of the week, the last day of the reserve maintenance period and US holidays for Model 2- during the third quarter of 2013, we obtained the expected total credits for the same ten banks using each model, and then computed the forecasting errors, ${ }^{18)}$ mean deviation errors ${ }^{19)}$ and mean absolute percentage errors ${ }^{20)}$ for each model to compare forecasting accuracy. The mean deviation error of Model 2 was closer to zero and the mean absolute percentage error of Model 2 was slightly smaller than those of Model 1. However, we found that $95.1 \%$ of actual total credits were contained within a $95 \%$ confidence interval of total credit of Model 1, and $94.9 \%$ of actual total credits within a $95 \%$ confidence interval of total credit of Model 2. Giving more weight to the result of confidence interval coverage, we reached a conclusion that predictions using the Model 1 regression are better than those using Model 2, and are quite reliable.

\footnotetext{
18) Forecasting Error $\left(e_{i}\right)=$ actual total credit value $\mathrm{e}_{\mathrm{i}}$ - estimated total credit value $\mathrm{e}_{\mathrm{i}}$

19) Mean Deviation Error $=\operatorname{mean}\left(e_{i}\right)$

20) Mean Absolute Percentage Error $=$ mean $\left(\left|\frac{e_{i}}{\text { actual total credit }_{\mathrm{i}}}\right|\right)$
} 


\section{Step 2. Calculating Expected Remaining Credits}

The total credits to bank $i$ 's settlement account on day $j$ are divided at time $\mathrm{t}$ into the cumulative credits to bank $i$ on day $j$ by time t and the remaining credit to bank $i$ on day $j$ from time th the end of BOK-Wire+ operation such as in the formulas below. Using this relation with information on the cumulative credits which the BOK knows on a real-time basis, and the expected total credits obtained from Step 1, we calculated the expected remaining credits of the ten banks at each half-hour period between 9:00 a.m. and 5:30 p.m. on each day of the third quarter of 2013.

$$
\text { ETcredit }_{i j t}=\text { Ccredit }_{i j t}+\text { ERcredit }_{i j t} \Rightarrow \text { ERcredit }_{i j t}=\text { ETcredit }_{i j t}-\text { Ccredit }_{i j t}
$$

In the occasional event where the expected remaining credits were negative, we set the expected value to 0 since the credits are by definition positive. This correction creates a slight bias in the results, but in turn decreases their variance.

\section{Expected Remaining Debits}

\section{Step 1. Calculating Expected Total Debits Using Regression Model}

To calculate the expected total debits to a bank, we again fit a linear regression model (Model 1) with the total debit as the response variable, and the bank, the day of the week and indicators for reserve maintenance days and US holidays, the trade value of bonds, and the trade value of spot exchange as predictors. More specifically, we fit the model below:

$$
\text { Tdebit }_{i j}=\beta_{i}^{\text {debit }}+\gamma^{\text {debit }} D_{j}+\delta^{\text {debit }} R_{j}+\zeta^{\text {debit }} U_{j}+\eta^{\text {debit }} \text { Bond }_{j}+\theta^{\text {debit }} F X+\phi_{i j}
$$

where Tdebit $_{i j}$ represents the total debits from bank i's settlement account on day $j ; \beta_{i}^{\text {debit }}$ is a constant effect for bank $i ; \gamma^{\text {debit }}$ is a vector of day of the week effects 
and $D_{j}$ a vector of day of the week indicators for day $j ; R_{j}$ is an indicator of whether day $j$ was the last day of the reserve maintenance period; $D_{j}$ is an indicator of whether day $j$ was a US holiday; Bond $d_{j}$ is the trade value of bonds on day $j-1 ; F X_{j}$ is the trade value of spot exchange on day $j-2$; and $\phi_{i j}$ is an error term, assumed to be normally distributed with different variance for each bank (heteroscedasticity).

We estimated the parameters of the above model by using fixed effect panel regression under hetroscedasiticity with the data from ten banks (ids 1, 27, 28, 30, 31, 32, 34, 58, 138 and 139) from 1 July 2012 to 30 June 2013. As a result of the regression, all coefficients of Model 1 except for the indicator of Friday, the trade value of bond and the trade value of spot exchange were statistically significant at significance levels of $1 \%$, and the model's adjusted R-squared was equal to 0.9679 . We again re-estimated the revised model (Model 2) excluding the indicator of Friday, the trade value of bonds and the trade value of spot exchange from Model 1 , and found that all regression coefficients were statistically significant with p-values less than 0.001, and that the model's adjusted R-squared was equal to 0.9681 .

Using the estimated parameters and information on independent variables of the two models - the day of the week, the last day of the reserve maintenance period and US holidays, the trade value of bonds and spot exchange for Model 1, and the day of the week, the last day of the reserve maintenance period and US holidays for Model 2 - during the third quarter of 2013, we obtained the expected total debits for the same ten banks using each model, and then computed the forecasting errors, mean deviation errors and mean absolute percentage errors for each model to compare forecasting accuracy. The mean deviation error of Model 1 was closer to zero and the mean absolute percentage error of Model 1 was smaller than those of Model 2. In addition, we found that $94.1 \%$ of actual total debits were contained within a 95\% confidence interval of total debits in both Model 1 and Model 2. On the basis of these results, we reached a conclusion that predictions using the Model 1 regression are better than those using Model 2, and are quite reliable. 


\section{Step 2. Calculating Expected Remaining Debits}

The total debits from bank $i$ 's settlement account on day $j$ are divided at time $t$ into the cumulative debits by bank $i$ on day $j$ by time $t$ and the remaining debits of bank $i$ on day $j$ from time $t$ to the end of BOK-Wire+ operation such as in the formula below. Using this relation with information on the cumulative debits which the BOK knows on a real-time basis, and the expected total debits obtained from Step 1, we calculated the expected remaining dedits of the ten banks at each half-hour period between 9:00 a.m. and 5:30 p.m. on each day during the third quarter of 2013.

$$
\widehat{E T d e d i t}_{i j t}=\text { Cdedit }_{i j t}+\text { ERdedit }_{i j t} \Rightarrow \text { ERdedit }_{i j t}=\text { ETdedit }_{i j t}-\text { Cdedit }_{i j t}
$$

Similarly to the case with the expected credits, in the occasional event where the expected remaining debits were negative, we set the expected value to 0 since the debits are by definition positive. This correction creates a slight bias in the results, but in turn decreases their variance. 
Table A1: Results of regressions for expected total credits

\begin{tabular}{|c|c|c|c|c|c|}
\hline \multicolumn{3}{|c|}{ Model 1} & \multicolumn{3}{|c|}{ Model 2} \\
\hline & Coef. & $t$ & & Coef. & $t$ \\
\hline tue & $-0.4463^{* * *}$ & -4.71 & tue & $-0.4420^{* * *}$ & -4.90 \\
\hline wed & $-0.7733^{* * *}$ & -7.72 & wed & $-0.7675^{* * *}$ & -7.88 \\
\hline thu & $0.4285^{* * *}$ & 4.72 & thu & $0.4529^{* * *}$ & 5.08 \\
\hline fri & $-0.1974^{*}$ & -2.17 & fri & $-0.1860^{*}$ & -2.06 \\
\hline reserve_check & $-5.0634^{* * *}$ & -34.42 & reserve_check & $-5.0582^{* * *}$ & -34.46 \\
\hline us_hol & $-1.1194^{* * *}$ & -6.80 & us_hol & $-1.1088^{* * *}$ & -6.78 \\
\hline bond & -0.0014 & -0.33 & - & - & - \\
\hline$f x$ & -0.0145 & -1.14 & - & - & - \\
\hline _Ireceiver_1 & $3.2454^{* * *}$ & 16.17 & _Ireceiver_1 & $3.0444^{* * *}$ & 29.52 \\
\hline _Ireceiver_27 & $12.3990^{* * *}$ & 56.58 & _Ireceiver_27 & $12.2016^{* * *}$ & 90.57 \\
\hline _Ireceiver_28 & $7.5387^{* * *}$ & 37.27 & _Ireceiver_28 & $7.3455^{* * *}$ & 69.65 \\
\hline _Ireceiver_30 & $13.7615^{* * *}$ & 61.23 & _Ireceiver_30 & $13.5581^{* * *}$ & 93.65 \\
\hline _Ireceiver_31 & $5.5641^{* * *}$ & 28.41 & _Ireceiver_31 & $5.3665^{* * *}$ & 57.94 \\
\hline _Ireceiver_32 & $15.5196^{* * *}$ & 68.50 & _Ireceiver_32 & $15.3199^{* * *}$ & 104.16 \\
\hline _Ireceiver_34 & $8.1727^{* * *}$ & 42.00 & _Ireceiver_34 & $7.9805^{* * *}$ & 88.51 \\
\hline _Ireceiver_58 & $2.9636^{* * *}$ & 14.64 & _Ireceiver_58 & $2.7652^{* * *}$ & 26.27 \\
\hline _Ireceiver_138 & $8.1447^{* * *}$ & 39.93 & _Ireceiver_138 & $7.9436^{* * *}$ & 72.84 \\
\hline _Ireceiver_139 & $7.4039^{* * *}$ & 37.51 & _Ireceiver_139 & $7.2040^{* * *}$ & 74.81 \\
\hline Number of obs & $=2480$ & & Number of obs & $=2490$ & \\
\hline$F(18,2462)$ & $=4018.74$ & & $F(16,2474)$ & $=4544.65$ & \\
\hline Prob $>F$ & $=0.0000$ & & Prob $>F$ & $=0.0000$ & \\
\hline $\mathrm{R}$-squared & $=0.9671$ & & $\mathrm{R}$-squared & $=0.9671$ & \\
\hline Adj R-squared & $=0.9668$ & & Adj R-squared & $=0.9669$ & \\
\hline
\end{tabular}

Note: ${ }^{*}{ }^{*}$ and $* * *$ represent statistical significance at the $5 \%, 1 \%$ and $0.1 \%$ level, respectively.

Comparison of measures of forecasting accuracy of regression models

\begin{tabular}{l|cc} 
& Model 1 & Model 2 \\
Man Deviation Error & -0.3822 & -0.3529 \\
\hline Mean Absolute Percentage Error (\%) & 19.66 & 19.41 \\
\hline
\end{tabular}


Table A2: Results of regressions for expected total debits

\begin{tabular}{|c|c|c|c|c|c|}
\hline \multicolumn{3}{|c|}{ Model 1} & \multicolumn{3}{|c|}{ Model 2} \\
\hline & Coef. & $t$ & & Coef. & t \\
\hline tue & $-0.2939^{* *}$ & -3.09 & tue & $-0.2692^{* *}$ & -3.49 \\
\hline wed & $-0.5075^{* * *}$ & -5.05 & wed & $-0.4879^{* * *}$ & -5.67 \\
\hline thu & $0.6049^{* * *}$ & 6.63 & thu & $0.6054^{* * *}$ & 7.93 \\
\hline Fri & -0.0128 & -0.14 & - & - & - \\
\hline reserve_check & $-5.2343^{* * *}$ & -35.43 & reserve_check & $-5.2310^{* * *}$ & -35.50 \\
\hline us_hol & $-1.0795^{* * *}$ & -6.53 & us_hol & $-1.0934^{* * *}$ & -6.82 \\
\hline bond & 0.0037 & 0.87 & - & - & - \\
\hline$f x$ & 0.0001 & 0.04 & - & - & - \\
\hline _Ireceiver_1 & $3.0615^{* * *}$ & 14.87 & _Ireceiver_1 & $3.1743^{* * *}$ & 31.34 \\
\hline _Ireceiver_27 & $12.0550^{* * *}$ & 38.07 & _Ireceiver_27 & $12.1676^{* * *}$ & 130.47 \\
\hline _Ireceiver_28 & $6.7873^{* * *}$ & 28.69 & _Ireceiver_28 & $6.9051^{* * *}$ & 80.15 \\
\hline _Ireceiver_30 & $13.5095^{* * *}$ & 59.61 & _Ireceiver_30 & $13.6257^{* * *}$ & 87.87 \\
\hline _Ireceiver_31 & $2.8790^{* * *}$ & 34.04 & _Ireceiver_31 & $2.9899^{* * *}$ & 32.92 \\
\hline _Ireceiver_32 & $19.3134^{* * *}$ & 56.84 & _Ireceiver_32 & $19.4082^{* * *}$ & 89.10 \\
\hline _Ireceiver_34 & $8.2016^{* * *}$ & 14.30 & _Ireceiver_34 & $8.3231^{* * *}$ & 118.77 \\
\hline _Ireceiver_58 & $2.3454^{* * *}$ & 68.63 & _Ireceiver_58 & $2.4588^{* * *}$ & 26.63 \\
\hline _Ireceiver_138 & $7.6201^{* * *}$ & 42.56 & _Ireceiver_138 & $7.7360^{* * *}$ & 87.08 \\
\hline _Ireceiver_139 & $6.0048^{* * *}$ & 11.62 & _Ireceiver_139 & $6.1261^{* * *}$ & 56.87 \\
\hline Number of obs & $=2480$ & & Number of obs & $=2490$ & \\
\hline$F(18,2462)$ & $=4159.70$ & & $F(15,2475)$ & $=5031.22$ & \\
\hline Prob $>F$ & $=0.0000$ & & Prob $>F$ & $=0.0000$ & \\
\hline R-squared & $=0.9682$ & & R-squared & $=0.9682$ & \\
\hline Adj R-squared & $=0.9679$ & & Adj R-squared & $=0.9681$ & \\
\hline
\end{tabular}

Note: ${ }^{*}{ }^{* *}$ and ${ }^{* * *}$ represent statistical significance at the $5 \%, 1 \%$ and $0.1 \%$ level, respectively.

Comparison of measures of forecasting accuracy of regression models

\begin{tabular}{l|c|c} 
& Model 1 & Model 2 \\
mean deviation errors & -0.0773 & -0.0982 \\
mean absolute percentage error (\%) & 18.80 & 18.92 \\
\hline
\end{tabular}




\section{References}

Ball, Alan, Edward Denbee, Mark J. Manning, and Anne Wetherilt (2011), "Intraday Liquidity: Risk and Regulation," Financial Stability Paper, No. 11, Bank of England.

Bank of Korea (2011), Financial Institutions in Korea.

Bank of Korea (2012), Payment and Settlement Systems Report.

Basel Committee on Banking Supervision (2013), "Monitoring Tools for Intraday Liquidity Management."

Becher, C., S. Millard, and K. Soramäki (2008), "The Network Topology of CHAPS Sterling," Bank of England Working Paper, No. 355.

Boss, M., H. Elsinger, M. Summer, and S. Thurner (2004), "The Network Topology of the Interbank Market," Quantitative Finance, Vol. 4, No. 6, pp. $677-684$.

Boss, M., G. Krenn, V. Metz, C. Puhr, and S.W. Schmitz (2008), "Systemically Important Accounts, Network Topology, and Contagion in ARTIS," OeNB Financial Stability Report, No. 15.

Craig, Ben and Goetz von Peter (2010), "Interbank Tiering and Money Center Banks," BIS Working Papers, No. 322, Bank for International Settlements.

Embree, L. and T. Roberts (2009), "Network Analysis and Canada's Large Value Transfer System," Bank of Canada Discussion Paper, No. 13.

Fricke, Daniel and Tomas Lux (2012), "Core-Periphery Structure in the Overnight Money Market: Evidence from the e-MID Trading Platform," Kiel Working Papers, No. 1759, Kiel Institute for the World Economy.

Fruchterman, Thomas M. J., and Edward M Reingold (1991), "Graph Drawing by Force-Directed Placement," Software - Practice \& Experience (Wiley) 21 (11): pp. 1129-1164.

Galbiati, M. and S. Giansante (2010), "Emergence of Networks in Large Value Payment Systems," DEPFID Working Paper. 
Heijmans, R., R. Heuver, and D. Walraven (2010), "Monitoring the Unsecured Interbank Money Market Using TARGET2 Data," De Nederlandsche Bank Working Paper, No. 276.

Jia, Y. (2011), "Macro-prudential Regulation from the Perspective of the Financial Network - An Empirical Analysis Based on the Data From Payment and Settlement System in China," Bank of China Journal of Financial Research, No. 4.

Langfield, Sam, Zijun Liu, and Tomohiro Ota (2013), "Mapping the UK Interbank System," Bank of England, European Systemic Risk Board and UK Financial Services Authorities.

Pröpper, M., I. van Lelyveld, and R. Heijmans (2009), "Towards a Network Description of Interbank Payment Flows," De Nederlandsche Bank Working Paper, No. 177.

Soramäki K., M. Bech, J. Arnold, R.J. Glass, and W.E. Beyeler (2007), "The Topology of Interbank Payment Flows," Physica A: Statistical Mechanics and Its Applications 379, No. 1, pp. 317-333.

Soramäki, K. and S. Cook (2013), "SinkRank: An Algorithm for Identifying Systemically Important Banks in Payment Systems," Economics: The OpenAccess, Open-Assessment E-Journal, Vol. 7.

Vitali S., J.B. Glattfelder, and S. Battiston (2011), "The Network of Global Corporate Control," PLOS ONE 6(10). 


\section{<Abstract in Korean >}

백승진 ${ }^{*}$, Kimmo Soramäki**, 윤재호***

본 연구는 Core-Periphery structure, SinkRank 등의 네트워크 분석기법을 활용하여 한은금융망내 중요 금융기관을 선별하고 동 기관들의 일중유동성 이용상황을 PS-LI(Payment System-Liquidity Index)라는 신규 지급결제지표를 구성하여 분석하였다.

한은금융망의 네트워크 구조는 금융기관들 상호간 자금 지급·수취가 빈번하게 발생하는 Corebank Group에 속한 참가기관과 주변부 참가기관으로 구분된다. 본 Core-Periphery structure로 한은금융망 자금결제 구조를 분석한 결과 한은금융망 참가기관(132개) 중 중요도가 높은 10 개의 Corebank를 식별하였으며 이들 Corebank Group에 속한 참가기관간 결제집중도는 Fedwire 등 다른 주요국 거액결제시스템에 비해 비교적 낮은 것으로 나타났다. 또한 Node(참가기관)간 결제금액을 기반으로 중요도를 측정하는 SinkRank 기법을 통해서도 CorePeriphery structure 결과와 거의 동일한 Corebank를 파악할 수 있었다.

이와 같이 파악한 한은금융망 중요기관들의 일중유동성 이용 상황은 보유유동성 대비 지급액 비율을 나타내는 PS-LI를 구성하여 분석하였다. 분석결과 대부분의 중요기관들은 낮은 PS-LI 수치를 보여 지급여력이 양호한 반면, 일부 기관은 높은 PS-LI 수치를 보여 일중유동성 여유 정도가 상대적으로 작은 것으로 나타났다. 중요 참가기관 중 일중유동성 여유규모가 작거나 동 규모의 변동성이 큰 기관은 금융시장에서 지급불이행 등이 발생하는 경우 여타 기관보다 한은금융망에 미치는 부정적 영향이 클 것으로 판단된다. 따라서 본 연구에서 다룬 네트워크 분석기법 및 PS-LI 지표는 한은금융망의 안정적 운영을 위한 모니터링 수단으로 유용하게 활용할 수 있을 것으로 기대된다.

* 한국은행 금융결제국 결제안정팀 조사역

** CEO, Financial Network Analytics Ltd

*** 한국은행 금융결제국 결제안정팀 과장 